\title{
Enhancing Transparency in the Supply Chain: An Information Processing Perspective
}

\begin{abstract}
While nowadays' need to enhance transparency in supply chains (TSC) seems undisputable, supply chain management (SCM) scholars and practitioners lack an operationalization of the phenomenon and a clear understanding of how to enhance TSC. This study aims to address this need by applying a multiple case study design with 24 awarded or industry-wide good practice solutions to disclose how focal companies can enhance TSC. Drawing on information processing theory (IPT), this study contributes to the understanding of the phenomenon by placing TSC in context and identifying 29 TSC determinants that have to be attained in order to enhance TSC. The study reveals that although the targeted effect of enhanced TSC is mainly beneficial for the focal company, it requires all relevant supply chain partners to enhance TSC. By presenting the TSC determinants that are required on an intra-firm and inter-organizational level to enhance TSC, we elaborate IPT in the context of TSC.
\end{abstract}

\section{Keywords:}

transparency; visibility; traceability; information processing theory; sustainability; supplier management; case study research 


\section{Enhancing Transparency in the Supply Chain: An Information Processing Perspective}

\section{INTRODUCTION}

Transparency in the supply chain (TSC) has become a topic of utmost importance in both research and industry (Kim \& Davis, 2016; Morgan, Richey, \& Ellinger, 2018) due to recent global value creation, the international division of labor, and outsourcing decisions (Min, Zacharia, \& Smith, 2019; Swift, Guide Jr., \& Muthulingam, 2019). The negative impacts of a lack of transparency have been emphasized in recent examples such as Evonik's explosion in 2012. (Yan, Choi, Kim, \& Yang, 2015) and Chipotle's E. coli outbreak in 2015² (Saberi, Kouhizadeh, Sarkis, \& Shen, 2018). As a result, decision makers are seeking to enhance transparency in processes outside of their organizational boundaries, and end-consumers and investors are demanding more traceability during products' journey through the supply chain (Gross, 2019). This forces organizations to identify critical suppliers and sub-suppliers (actors) in their supply chain to avoid poor brand awareness. In one deterrent example, Cargill, an agricultural heavyweight, earned the dubious honor of being "the worst company in the world" (Mighty Earth, 2019) after quickly turning from a company with laudable standards into the "devil's advocate" (Yaffe-Bellany, 2019). Consequently, the subject matters of TSC are processes, actors and products flowing through the supply chain networks.

Despite its relevance, the phenomenon of TSC is still understudied in the field of operations management (OM) and supply chain management (SCM (Wieland, Handfield, \& Durach, 2016). The authors rank TSC as the fourth most relevant but understudied topic in OM and SCM, as the

\footnotetext{
${ }^{1}$ In 2012, an explosion at an Evonik Industries site disrupted the entire automotive industry, as Evonik produced 50\% of all PA 12 worldwide. The dependency was not known to most original equipment manufacturers.

${ }^{2}$ In 2015, two E. coli outbreaks infected 58 customers of Chipotle Mexican Grill Restaurants. The chain was unable to monitor its suppliers and withdraw the infected products from its restaurants.
} 
number of contributions involving TSC is increasing but remains fragmented. To date, contributions have focused on selected facets of the phenomenon, such as conflict mineral disclosure Swift et al. (2019), supplier transparency Morgan et al. (2018), or visibility and flexibility as complements to analytics in the supply chain Srinivasan and Swink (2018). Thus, the overall picture of TSC remains fragmented. Moreover, the phenomenon lacks clear operationalization, which leads to misuse and makes it ill-defined, according to Williams, Roh, Tokar, and Swink (2013). Newly emerging digital technologies, such as distributed ledger technologies (DLT), the internet of things (IoT), artificial intelligence (AI), and digital twins, have the potential to improve TSC (Hofmann, Sternberg, Chen, Pflaum, \& Prockl, 2019). Consequently, many decision makers have aimed to enhance TSC through DLT pilot projects (Roeck, 2020), but they have found little success to date (Sternberg, Hofmann, \& Roeck, 2020). Some of the pilot projects involve rather pointless applications of the emerging technology and seem to simply aim to take advantage of the hype surrounding the technology (Wang, Han, \& Beynon-Davies, 2018). As academic scholars have not provided practitioners with a profound understanding of what it takes to enhance TSC or a frame with which to assess the contributions of digital technologies such as DLT, IoT AI, or digital twins, the desperate hope to enhance TSC with any of these emerging technologies is a logic consequence. Swift et al. (2019) highlight this as a research gap: “[...] we did not directly observe how firms improved their SCV [supply chain visibility]. It would be interesting to understand what specific steps firms take to improve SCV [supply chain visibility] and analyze how each contributes to improved operating performance" (p. 426). In other words, the authors claim the lack of transparency on the enhancement of TSC, as visibility can be understood as a part of TSC (Morgan et al., 2018). The current research aims to fill this void by answering the following research question (RQ): 
RQ: How can firms enhance transparency in the supply chain?

In order to address the RQ, it is necessary to gain a clear picture of the TSC phenomenon by examining focal companies' motivation to enhance TSC, deployment of solutions to enhance TSC, and resulting level of TSC. The RQ leads to the exploration of the TSC determinants as they represent the requirements to fulfill in order to enhance TSC from the perspective of the focal company. As the phenomenon of TSC is rather complex, we apply an inductive multiple-case study to answer the RQ based on in-depth data. Specifically, we study 24 different cases that were identified as award-winning or industry-wide good practice solutions for enhancing TSC to understand what it takes to enhance TSC for the focal company. We mainly apply information processing theory (IPT) as a theoretical lens to explore how organizations can enhance TSC. After reviewing the literature and describing our research approach, we present the mechanisms for enhancing TSC and identify the TSC determinants. Then, we use abductive reasoning by drawing on extant literature to develop a model for answering our RQ. This allows us to derive eight propositions regarding the relationships between the core elements of TSC. Thereby, we contribute a mid-range theory on the phenomenon of TSC. We conclude by summarizing our findings and providing suggestions for future research.

\section{LITERATURE BACKGROUND}

\section{Transparency research in supply chains}

Physically, transparency can be defined as an optical property of object (a) that can be seen through and that allows the appearance of a second object (b) behind object (a). Practitioners and academic scholars in the field of SCM apply this definition in a metaphorical way. Our field of study defines the organizational boundary as object (a), given the state that a focal company is generally unable 
to see through the organizational boundary of external supply chain partners (e.g., suppliers, subsuppliers, or logistics service providers) and their key characteristics and affiliated processes and products as object (b). From this perspective, TSC refers to a state of an inter-organizational network or part of a network that enables an element behind the organizational boundary to be visible from the perspective of a focal company. SCM scholars (e.g., Williams et al., 2013) tend to agree on the inter-organizational nature of TSC, which means that the object of interest is situated outside of the sphere of the focal company in another node (e.g., an organization including its characteristics) or along an edge (e.g., in transit). However, SCM scholars vary their focus, as they stud TSC in upstream (e.g., Morgan et al., 2018) and downstream supply chain partners (e.g., Jin, Williams, Tokar, \& Waller, 2015), with the focus on products (e.g., Aung \& Chang, 2014) or processes (e.g., Steinfield, Markus, \& Wigand, 2011) within the supply chain. In addition, they discuss TSC in various contexts, including improvement of decision-making (Kent \& Mentzer, 2003), risk mitigation (Basole \& Bellamy, 2014), responsiveness (Williams et al., 2013), product safety (Costa, Antonucci, Pallottino, Aguzzi, Sarriá, \& Menesatti, 2013), collaboration (Holweg, Disney, Holmström, \& Småros, 2005), and sustainability (Carter \& Rogers, 2008).

The broadness of foci and contexts in prior literature are reflected in the variety of definitions of TSC proposed by SCM scholars (Egels-Zandén, Hulthén, \& Wulff, 2015). For instance, some authors, like Cramer (2008) and Miller, Fugate, and Golicic (2017), focus on the disclosure of sustainability information about supply chain actors to the end-consumer in their definitions. Others, such as Doorey (2011), define TSC as the ability to track a product in a supply chain, thus placing traceability and transparency at the same level. In addition, the term "visibility," as an enabler of TSC, is used interchangeably with "information sharing" (Barratt \& Oke, 2007). However, information sharing is an activity that is required to enable visibility. Therefore, 
information sharing can be regarded as an antecedent of TSC (Barratt \& Oke, 2007). We rely on Carter and Easton (2011), who define TSC as "proactively engaging and communicating with key stakeholders and having traceability and visibility into upstream and downstream supply chain operations" (p. 49). Visibility is defined as the ability to "access to high-quality information that describes various factors of demand and supply" (Williams et al., 2013, p. 545), while traceability can be understood as "the ability of a system to indicate the current or historical state of activities" (Cheng \& Simmons, 1994, p. 4).

In addition to a variety of foci, contexts, and definitions, the literature addresses a broad range of motivations and targeted effects of enhanced TSC. Research presents the need for supply chain actors to reduce demand and supply uncertainties as a motivation for enhancing TSC (Oliva \& Watson, 2009), while other contributions identify the need to reduce uncertainty about the quality and sustainability of products (Costa et al., 2013) and the corporate social responsibility (CSR) of upstream supply chain actors (Gold, Seuring, \& Beske, 2010; Rauer \& Kaufmann, 2015) as motivations. Reducing the operational uncertainties stemming from supply chain disruptions and poor operational performance of suppliers (Ivanov \& Dolgui, 2018; Tomlin, 2006) have also been identified as motivations to enhance TSC. According to Holweg et al. (2005), supply chain actors enhance TSC when seeking to reduce uncertainty that prevents them from achieving a high level of supply chain performance. In these situations, they aim to achieve specific effects, such as improved planning and replenishment (Jin et al., 2015; Wadhwa, Mishra, Chan, \& Ducq, 2010), resilience (Brandon-Jones, Squire, Autry, \& Petersen, 2014; Gunasekaran, Subramanian, \& Rahman, 2015), or avoidance of quality (Costa et al., 2013) and CSR issues (Zhu, Song, Hazen, Lee, \& Cegielski, 2018). 


\section{TSC mechanisms}

Given the variety of different motivations and targeted effects, the literature reveals that different TSC mechanisms are deployed to enhance TSC. These mechanisms describe solutions that are composed of technologies, structures, and processes. Seven types of mechanisms have been differentiated ${ }^{3}$ :

- Screening and assessing ( $S \& A)$ : Enhancing the visibility of specific characteristics (e.g., capabilities) of external organizations and their processes (e.g., potential suppliers) to enable evaluation before engaging with them and signing a contract (e.g., Wan \& Beil, 2009).

- Forecasting ( $F o$ ): Enhancing the visibility of the future product demand of customers or supply of external suppliers to improve planning and production decisions (e.g., Oliva \& Watson, 2009).

- Monitoring (Mo): Enhancing the visibility of the performance of external supply chain partners to maintain surveillance over their operations (e.g., McFarlane \& Sheffi, 2003).

- Tracking and tracing (T\&T): Enhancing the visibility of a product's current position in the supply chain and condition as well as gaining traceability of products' history to identify problems or deviations at the product level (e.g., Kärkkäinen, Ala-Risku, \& Främling, 2004).

- Mapping (Ma): Enhancing the visibility of the involved supply chain partners and their locations, value contributions, and processes within the supply chain in order to identify dependencies and inefficiencies and mitigate risks (e.g., Gardner \& Cooper, 2011).

\footnotetext{
${ }^{3}$ SCM scholars use slightly different expressions (e.g., "event watching" is also referred to as "supply chain disruption management"), but we will use the following terms consistently throughout this paper.
} 
- Event watching (Ew): Enhancing the visibility of the involved supply chain partners and the flow of products and money to identify and react to incidents and disruptions (e.g., Tomlin, 2006).

- Auditing (Au): Enhancing the visibility of specific characteristics (e.g., value contributions) of supply chain partners (e.g., suppliers) during established, contractual relationships (e.g., Kovács, 2008).

All seven TSC mechanisms rely on technology (Zhu et al., 2018), particularly information technology (IT). To manage the volume, variety, and velocity of data in contemporary supply chains, state-of-the-art TSC solutions employ cloud computing, big data analytics and machine learning algorithms (Wang, Gunasekaran, Ngai, \& Papadopoulos, 2016). Such solutions may also include image recognition, sensors, radio frequency identifiers, geo-fencing, and global positioning systems (Cegielski, Allison Jones-Farmer, wu, \& Hazen, 2012; Oliveira, Cardoso, Barbosa, da Costa, \& Prado, 2015; Visich, Li, Khumawala, \& Reyes, 2009). Furthermore, several blockchain and DLT pilots indicate the potential of the novel technologies to enhance products' traceability and processes' visibility (Wang, Singgih, Wang, \& Rit, 2019). Overall, the literature emphasizes the importance of technology as an enabler of TSC mechanisms. However, as Zhu et al. (2018) note, the use of technology does not imply successful TSC per se. Technology is one element that enables TSC mechanisms, but it is not the only one.

In addition to technologies, the literature has revealed data-related antecedents of TSC, including data accessibility, accuracy, availability, and timeliness (Srinivasan \& Swink, 2018; Williams et al., 2013; Zhu et al., 2018), which would qualify as determinants. These data antecedents are necessary, but they are not sufficient for enhancing TSC alone; Cegielski et al. (2012), Morgan et al. (2018), and Zhu et al. (2018) underline the importance of collaboration between supply chain 
partners and communication for enhancing TSC and thus suggest to go beyond these data-related antecedents. Moreover, not all TSC mechanisms are affected by technologies in the same way, and their motivations and target effects are quite different. Thus, generalizing the few known antecedents for all TSC mechanisms does not sufficiently account for the heterogeneity of the TSC mechanisms. This is a gap in the extant literature.

\section{Theoretical grounding of transparency in supply chains}

In order to understand TSC and its components, it is necessary to analyze its theoretical grounding. In addition to transparency in SCM, management scholars have discussed transparency in organizations, applying theoretical lenses such as organizational learning (Bernstein, 2012), agency theory (Schnackenberg \& Tomlinson, 2014), and transaction cost economics (Granados, Kauffman, \& King, 2008). Given the focus of our study, we concentrate on theories that can explain the inter-organizational components of TSC.

SCM scholars draw on the resource-based view, dynamic capabilities, contingency theory, and IPT when studying TSC. The resource-based view has been applied to explore the sources of competitive advantage. Enabling visibility in supply chains is seen as an antecedent of sustainability performance (Dubey, Gunasekaran, Childe, Papadopoulos, Luo, \& Roubaud, 2017) and supply chain resilience (Brandon-Jones et al., 2014). Barratt and Oke (2007) apply the resource-based view to identify the antecedents of visibility in supply chains for achieving a competitive advantage, and Wang and Wei (2007) and Steinfield et al. (2011) use the resourcebased view to study competitive advantage as a result of achieved TSC. While these authors focus on the competitive advantage, the role of TSC, its enabler visibility and corresponding antecedents vary in their contributions. Similar to the resource-based view, the theory of dynamic capabilities has been applied by SCM scholars focusing on the capabilities required to achieve a competitive 
advantage. Brusset (2016) identifies visibility as one of the three capabilities needed to enhance agility in supply chains as a competitive advantage, while Liu, Ke, Wei, and Hua (2013) describe visibility as one of four second-order constructs of agility in supply chains. Contingency theory has been applied to study the context of phenomena related to TSC. For example, Brandon-Jones et al. (2014) examine the contingencies of supply chain resilience, including connectivity and information sharing as predictors of visibility, and identify visibility as an antecedent of resilience. Caridi, Crippa, Perego, Sianesi, and Tumino (2010) explore the effect of supply chain configurations on visibility, while Wamba and Chatfield (2009) apply contingency theory to identify contingency factors affecting TSC as a result of radio frequency identification (RFID) use. Finally, SCM scholars have applied IPT to focus on adequate information processing and required capabilities in the context of TSC. Srinivasan and Swink (2018) draw on IPT to examine the role of visibility as an enabler of supply chain analytics, and Williams et al. (2013) use it to examine responsiveness of supply chains. Furthermore, Zhu et al. (2018) use IPT to explore analyticsenabled TSC.

Our RQ positions TSC as the focus of the study and asks how firms can enhance TSC, which is best explored through the lens of IPT. This leads to a necessary exploration of the determinants of enhanced TSC. Given the described inter-organizational scope of TSC, exploring determinants requires to understand information processing across organizational boundaries in the supply chain. Williams et al. (2013) stated that IPT can help researchers understand the bigger picture, underlining that addressing data antecedents is not sufficient to enhance TSC. Moreover, the SCM literature illustrates that supply chain partners seek to reduce different types of uncertainties in their supply chains via TSC mechanisms. This aligns with the logic of IPT, meaning that IPT is well- 
suited for use as a theoretical lens to study how firms can enhance TSC and gain a complete picture of this phenomenon and its determinants.

\section{Information processing theory and transparency in supply chains}

IPT emerged from organizational research that aimed to explore intra-firm information processing (i.e., between different sub-units within an organization). Following Galbraith (1974) and Tushman and Nadler (1978), IPT characterizes organizations as open social systems that aim to mitigate uncertainty in order to increase their performance. The theory consists of three elements: information processing need (IPN), information processing capability (IPC), and the fit between IPN and IPC (Bensaou \& Venkatraman, 1995; Tushman \& Nadler, 1978). IPN stems from uncertainty. In the intra-firm context, three types of uncertainties have been identified: sub-unit task characteristics, sub-unit task environment, and inter-unit task interdependence (Tushman \& Nadler, 1978). According to Galbraith (1974), an organization can address uncertainty-triggered IPN in two ways: (i) by reducing the IPN or (ii) by increasing the IPC. The first option requires building up slack or enabling self-contained tasks, and the second option requires investment in vertical and cross-functional IT (e.g., enterprise resource planning (ERP) systems) or extension of lateral relationships (e.g., direct contact, task force).

Premkumar, Ramamurthy, and Saunders (2005) were the first to apply IPT in an interorganizational context. In their contribution, they developed a taxonomy for IPNs and IPCs. In the inter-organizational context, different types of uncertainties, such as demand uncertainty, supply uncertainty, and product criticality, trigger IPNs for supply chain actors, increasing the focal company's need to enhance TSC (Premkumar et al., 2005; Williams et al., 2013). Accordingly, the focal company can either (i) reduce IPN by building up slack (e.g., inventory) and thereby avoid enhancing TSC or (ii) increase IPC by deploying a TSC mechanism. BY deploying a TSC 
mechanism, the focal company invests in vertical IT that fosters information processing across organizational boundaries (e.g., collaborative EDI-based forecasts) and extends lateral relations, including joint structures, processes, and meetings with external supply chain partners (e.g., supplier days). The degree of investment in inter-organizational vertical IT, also referred to as interorganizational information systems (IOIS), and extension of cross-company lateral relations depends on the TSC mechanism that is deployed. As prior illustrated by the role of IT for auditing, the TSC mechanisms vary in their dependence on IT, structures and processes, as Bensaou and Venkatraman (1995) found in general for information processing. By deploying TSC mechanisms in the supply chain, focal companies can increase their IPC and thus establish a fit with their specific IPN. This, in turn, leads to enhanced TSC, ultimately achieving the target effect. However, this fit can be achieved only if IPCs can be successfully built up in the supply chain and match the focal company's IPNs. Thus, IPCs require cross-company deployment of the specific TSC mechanism. For each TSC mechanism, there are a set of specific determinants that define the success of deployment, which take effect at the intra-firm and inter-organizational level. However, extant research on IPT has focused only on the intra-firm perspective, without illuminating interorganizational information processing and the corresponding IPCs. Hence, it is necessary to elaborate on IPT within the inter-organizational setting of supply chains. Our study addresses this gap.

\section{RESEARCH DESIGN}

Extant research has identified motivations to enhance TSC and the targeted effects of doing so. However, how firms can enhance TSC and the determinants that must be addressed remain largely unexplored. Hence, we adopt an inductive, multiple-case study research design with abductive reasoning to develop a mid-range theory concerning the determinants of TSC (Ketokivi \& Choi, 
2014), which sheds light on an unexplored phenomenon and lays the groundwork for future research (Edmonson \& McManus, 2007; Meredith, 1998). An inductive case study enables us to gain a deep understanding of the phenomenon under study, which is needed to answer the RQ and identify the TSC determinants that play a pivotal role in enhancing TSC from the perspective of the focal company (Eisenhardt, 1989; Gerring, 2004). Abductive reasoning was chosen because our research aim is to exploit IPT in the inter-organizational context of TSC. Given the diversity of TSC mechanisms, our case study adopts a holistic, multiple-case design in which the determinants are the unit of analysis and the TSC mechanisms are the units of observation (Yin, 2017).

\section{Sampling of cases}

To identify the TSC determinants, we studied applied and leading solutions that employ the seven TSC mechanisms. Our RQ required applied TSC solutions, as we aim to study functioning realworld applications. Moreover, we decided to observe only leading solutions in order to study the phenomenon of TSC based on a successful deployment of the observed TSC mechanism. To identify the leading solutions, we applied two selection criteria. Each of our cases adheres to one of the criteria:

1. Independently awarded solutions: The TSC solution received a competitive award (among multiple nominees) from an independent jury in the field of operations and supply chain management. Examples of such awards are the Supply Chain Innovation Award awarded by the Council of Supply Chain Management Professionals (CSCMP) or the Automotive Logistics Award awarded by the German Association of the Automotive Industry.

2. Industry-wide good practice solutions: The TSC solution resulted in enhanced TSC compared to the initial level and the supply chains of competitors. The initial level was 
typically identified as a problem, leading to motivation to improve the level of TSC. At best, this improved level of TSC was indicated by key performance indicators (e.g., ontime delivery, lead time).

We applied theoretical sampling in accordance with Glaser and Strauss (1967) to build our midrange theory. Following this approach, we added new cases to expand the emerging theory until saturation was achieved and no novel findings could be generated (Eisenhardt, 1989). As there are seven TSC mechanisms, we required at least 14 cases, assuming that saturation would be achieved after two cases ${ }^{4}$. While at first, we only defined the first criterion, this led us to define the second selection criterion, as we realized that the number of cases from awarded transparency solutions would be insufficient to cover all TSC mechanisms.

Based on the selection criteria, we started to identify potential cases. First, we identified a number of SCM awards and sought potential case candidates. In this step, we identified 37 award-winning companies (selection criterion 1) and approached all of them via email and telephone. We described our research initiative and asked if they were willing to participate in our study. Five candidates were willing. Second, via email or telephone, we contacted 135 companies in different industries to identify additional case candidates that deployed industry-wide good practice solutions (selection criterion 2). We asked them to indicate whether they deployed a promising solution to enhance transparency in their supply chains and whether they would be willing to participate in our study. In total, we acquired 27 additional cases and arranged interview appointments.

\footnotetext{
${ }^{4}$ As shown in Table 1, saturation was achieved after three to four cases.
} 


\section{Data collection}

Before conducting the interviews, we crafted our case study protocol based on the seminal work of Yin (2017), building on extant TSC research to ensure construct validity. The interview protocol contained a case study instrument that constituted the line of inquiry during the interviews. This instrument consisted of three parts:

1. Questions about the general understanding of TSC and its importance.

2. Questions about the usage of each of the seven TSC mechanisms to enhance TSC.

3. Questions about the selected TSC mechanisms.

While the first and the third parts were used in all cases, the second part was applied only in cases with industry-wide good practice solutions (selection criterion 2). These questions took the form of a self-assessment, enabling us to study applied and leading solutions according to selection criterion 2. Eight of the 27 additional cases did not reveal sufficient evidence in the interviews to justify selection. Thus, we acquired five award-winning solution cases and 19 industry-wide good practice cases - a total of 24 cases - at which point saturation was achieved.

The interview instrument contained questions that focused on the strategic and operational levels. If the interviewees did not cover both levels, we conducted additional interviews. In some cases, there was a need to interview external partners (e.g., suppliers, solution providers) to obtain a complete picture of the studied TSC solution. In these cases, we asked the interviewee to introduce us to additional internal or external stakeholders in order to achieve saturation within the cases. The number of interviews required for each case varied between one and six. The duration of the interviews varied as well depending on the complexity and number of interviewees required (see Table 1). Most of the case interviews were conducted on-site, which allowed us to see 
demonstrations of the TSC solutions (e.g., software tools, videos) and study additional data, such as process maps, auditing templates, and tracking devices. In addition, we collected secondary data from web sites, press releases, and newspaper articles to enable data triangulation. This allowed us to alleviate interviewer bias and increase reliability and construct validity (Jick, 1979; Yin, 2017). Twenty-two of 24 interviews were audio-recorded and subsequently transcribed. In addition, the researchers took extensive notes during the interviews. The transcripts were sent to the interviewees for review to ensure accuracy. Afterwards, all data were collected in a case database to enhance reliability and enable subsequent data analyses.

Insert Table 1 about here

\section{Data analysis}

For our data analysis, we followed the three-stage coding procedure described by Glaser (1992), which includes open coding, selective coding, and theoretical coding. Throughout the three stages, we moved from our inductive cases to abductive reasoning, enabling us to further exploit and combine existing theory on IPT with empirical data from our 24 cases (Alvesson \& Kärreman, 2007). We applied a mid-range coding approach that allowed us to derive codes from our empirical data and the literature (Urquhart, 2013). We also drew on the aforementioned literature on TSC and the a priori constructs and theoretical lenses that have been applied in relation to this phenomenon. The three-stage grounded theory procedures described by Glaser (1992) were used as a method for data analysis. To ensure smooth coding and analysis, we used Atlas.ti.

In the first stage of our coding procedure, we created open codes by drawing on the work of Gioia, Corley, and Hamilton (2013) for the first- and second-order codes. In our first open coding run, we created interviewee-centric first-order codes that used the terminology of the interviewees to 
account for organization- or industry-specific terms. As these first-order codes were descriptive in nature, we generated analytical second-order codes to synthesize specific terms and move from descriptive to analytical codes in the second run. Using the rich data set obtained for all cases, we developed detailed case descriptions, which enabled us to comprehend the big picture regarding the unit of observation. Specifically, we understood the motivations to enhance TSC via specific TSC mechanisms, the TSC determinants, and the target effects. Only by analyzing all three parts could we understand the interrelationships in depth.

In the second stage of our coding procedure, we performed selective coding to identify the codes that help answer our RQ. We identified the emerging codes and synthesized them into core categories for our RQ. Different colors were applied to the codes in Atlas.ti to continuously focus our attention on the RQ and avoid digressing. After merging the codes, we identified a total of 29 codes that described the TSC determinants.

In the third stage of our coding procedure, we applied theoretical coding, identifying and describing the relationships between the selected codes. We followed an abductive approach, drawing on ideas about the relationships described in the SCM literature.

\section{ENHANCING TRANSPARENCY IN THE SUPPLY CHAIN}

\section{TSC mechanisms}

We summarize three to four cases for each of the seven TSC mechanisms, outlining the initial uncertainty and motivation to enhance TSC, the TSC mechanism itself, the fit between IPN and IPC, the level to which TSC was enhanced, and the applied technologies.

Screening and assessing: The focal companies in Cases 8, 15, 22, and 23 reported uncertainty regarding different performance dimensions - including operational performance, financial 
stability, sustainability performance, communication capabilities, and the innovativeness of potential new suppliers - as a motivation to enhance TSC. The uncertainty created an IPN for greater transparency in different dimensions of the performance of potential suppliers before the focal companies engaged in a long-term business relationship with them spanning multiple years. By deploying screening and assessing as a TSC mechanism, the focal companies sought to ensure successful business relationships and identify risks or areas for improvement before establishing supply chain relationships. All cases feature a comprehensive IPN that includes all the aforementioned performance dimensions. Thus, the observed solutions in these cases enable transparency in multiple dimensions, which requires aggregating information from multiple parties, including the supplier, providers of external testimonials, third-party data providers (e.g., EcoVadis, RapidRatings), and actors and departments from the focal company (e.g., procurement, $\mathrm{R} \& \mathrm{D}$, quality). Moreover, the observed solutions are anchored in an established, obligatory process of supplier selection. By aggregating and combining information from different angles and stakeholders and by embedding the TSC mechanism in an internal business process, the focal companies could enhance TSC regarding potential suppliers, ultimately leading to a reduction in quality issues and risk exposure in the observed cases. For screening and assessing, the focal companies used standardized databases, which enabled easy data entry via web portals or several upload interfaces.

Forecasting: In Cases 2, 7, 9, and 13, the focal companies faced uncertainty regarding future demand and supply. On the customer side, they needed more accurate and timely information about future demand, while on the supplier side, they needed timely, accurate, and comprehensive information about future production capacity and the current inventory levels of their suppliers. These IPNs led the companies to establish advanced forecasting solutions as a TSC mechanism to 
enhance transparency regarding future demand and supply. The analyzed solutions are characterized by timely distribution and diffusion of information, matching demand and supply forecasts, and application of state-of-the-art technologies and forecasting methods. First, advanced technologies, including big data analytics (BDA) and artificial intelligence (AI), are used to aggregate and analyze customer data, economic data, and internal estimations. This allows forecast data for several time horizons to be generated and continuously updated at the product level for the focal company. Then, the forecast data are automatically broken down into individual product components. The required future supply is derived by automatically matching these numbers with the inventory level of the focal company and the suppliers (only in Cases 7 and 13). Electronic data interchange (EDI) and customized web portals enable timely information processing from the customer to the supplier, providing automated and timely forecasts for the customer, focal company, and supplier. Thereby, the observed forecasting solutions address the need for accurate and timely information processing to address the demand and supply uncertainty. As a consequence, the lead time and inventory level were reduced in all the observed cases.

Monitoring: In Cases 3, 5, and 12, the focal companies faced uncertainty within various performance dimensions, such as delivery reliability, service level, product quality, and sustainability of their supply chain partners, including suppliers and logistics service providers (LSPs). Given that the associated processes were outside of the focal companies' power, uncertainty led to an IPN to increase transparency regarding external supply chain processes. While the scope in all three cases varied, all focal companies established a monitoring mechanism that included three steps: data gathering, data analysis, and reactive measures. Data gathering solutions combined traditional data sources, such as EDI data transfer and ERP systems, with state-of-theart sensors, image recognition, and machine learning algorithms. Then, the data were processed 
and analyzed by the focal company and deviations were identified. Third, the focal companies initiated a dialogue with their supply chain partners based on the severity of the deviations. In these dialogues, additional data was exchanged to identify the root causes of deviations and develop countermeasures. By deploying monitoring as a TSC mechanism, the focal company enhanced TSC, which led to significant improvements in performance. For example, after the monitoring solution was introduced in Case 5, the replenishment time for most projects was reduced from 120 days to 30 days and the focal company and its suppliers increased delivery reliability to well over 95\%. In Cases 3 and 12, the number of quality and sustainability incidents was reduced by a low double-digit percentage.

Tracking \& tracing: In Cases $11,14,18$, and 20, the focal companies faced uncertainty regarding the timely delivery of products and components that are in transit after being consigned at the supplier site. Thus, the focal companies wanted to enhance transparency regarding products in transit to ensure they could react to unplanned deviations and reduce the risk of production stops due to delayed deliveries. To achieve this transparency, the focal companies established tracking and tracing solutions in collaboration with their suppliers and the associated LSPs. These tracking and tracing solutions enabled them to gather and process data in almost real time using positioning data (e.g., GPS) from telematics systems, third-party data providers (e.g., VesselFinder), or smartphones' GPS to track shipments for smaller supply chain partners and LSPs. In Cases 14 and 18 , the solutions were built on an integrative IT layer that enables aggregation of data points from different sources and transfer formats (e.g., JSON, REST, HTML) to achieve carrier- and modalityindependent visibility of all relevant shipments. This data is combined with schedules to identify deviations, which are visualized in a dashboard. Thereby, uncertainty is addressing by enhancing 
transparency with timely data processing and detection of deviations. Consequently, the focal companies were able to reduce the number of production stops and costs for express deliveries.

Mapping: Cases 4, 17, and 21 are examples of focal companies in different industries that addressed uncertainty regarding inadequate behavior of their upstream supply chain partners or the inherent operational risks of these partners. While operational risks might stem from natural hazards (e.g., earthquakes) or incidents (e.g., fire), inadequate behavior is caused by process, quality, sustainability, or CSR issues. Thus, the focal companies identified an IPN to gain visibility in their upstream supply chain and make the involvement of relevant actors transparent. In the aforementioned cases, the focal companies applied mapping solutions to address this IPN. These solutions comprise three steps. First, the focal companies defined the scope (i.e., the information of interest), which varies based on processes (Case 17), adherence to sustainability practices (Cases 4, 17, and 21), and quality practices (Cases 4, 17, and 21). Second, the focal companies engaged with their tier-1 suppliers, sometimes with the support of a third-party provider (Case 4), to gather relevant data from the suppliers. If the relevant supply chain actors were further upstream, they sought to engage their sub-suppliers by the support of their direct suppliers. Third, once the data were gathered, they were aggregated and analyzed by the focal company or a third-party provider to identify risks and define measures in collaboration with the corresponding supplier or subsupplier. Based on the defined scope, all cases demonstrated enhanced TSC, often focusing on subsuppliers. In Case 17, the focal company was able to make the business processes of the supplier visible and develop improvement measures to reduce both quality issues and lead times. This mechanism is able to work without advanced technology, aside from traditional databases and cloud solutions. 
Event watching: In Cases 1, 19, and 24, the focal companies faced uncertainty regarding disruptions and incidents (e.g., armed conflicts, natural disasters, strikes) in their supply chain. In contrast to mapping, this uncertainty is based on events that have occurred and for which there are no contingencies. Thus, the focal companies had an IPN to identify such disruptions as soon as possible and react to them in order to avoid supply shortages, production stops, or unplanned express deliveries. The focal companies deployed several IT tools based on a supply chain map and continuously analyzed different data sets (e.g., news, weather data, catastrophic reports) from multiple sources (e.g., Bloomberg, Reuters, social media) to identify supply chain disruptions and incidents. These IT tools draw on machine learning algorithms (specifically supervised learning) to continuously improve the accuracy and relevance of identified events. When identifying events, the IT tools send alerts to the focal company and, in Cases 19 and 24, enabled direct communication between the focal company and the affected supplier to clarify the impact of the disruption. Furthermore, the solutions implemented by the focal companies have an interface with the internal ERP system and warehouse management systems to directly increase transparency regarding the affected components at the inventory level. By deploying event watching solutions, the focal companies enabled timely identification of supply chain disruptions and actions to address the IPN. The achieved enhancement in TSC allowed the focal companies to reduce the reaction time (in Case 1, from 48 hours to 12 hours), thereby improving resilience and responsiveness.

Auditing: Cases 6, 10, and 16 are examples of focal companies that faced uncertainty regarding the operational, quality, or sustainability performance of their established suppliers. Thus, they identified an IPN to increase transparency regarding the suppliers' processes and capabilities to better evaluate future business relationships and identify improvement measures. The focal companies used standardized audits to achieve greater transparency regarding the relevant 
suppliers. In contrast to screening and assessments, audits are conducted in cases with an established business relationship and in which at least one business transaction has been processed. Before conducting the audit, several stakeholders in the focal company (e.g., procurement, quality, production, or logistics) are consulted and involved in the audit process. These stakeholders define the information that must be gathered and analyzed during the audit. The involvement of multiple functions enables transparency to be achieved in all relevant areas and a comprehensive audit to be performed based on expert knowledge from different angles. In the observed cases, a group of experts and a lead auditor (who orchestrates the audits) conducted site visits to the supplier and asked for all required information. In addition, information from third-party providers (e.g., certification institutions) was requested. After gathering all relevant data, the group assessed the data and crafted an auditing report that described the current situation at the supplier and provided recommendations and measures for the focal company and the supplier. By defining specific goals and deadlines, the focal companies sought to improve the performance of the supplier. By deploying audits, the focal companies enhanced transparency for a specific, and often critical, supplier, thereby addressing the IPN. None of the cases exhibited advanced use of technology; rather, they relied on traditional databases and user-friendly auditing tools.

\section{TSC determinants}

Based on our descriptions of the TSC mechanisms above, in this section we present the corresponding TSC determinants. These TSC determinants serve as requirements for deploying TSC mechanisms and thus enabling fit between the IPN and IPC. In total, our empirical data revealed 29 determinants, which are illustrated in Table 2 . These determinants can be clustered into five different groups based on their similarity to each other. First, the data determinants describe the data requirements for specific TSC mechanisms. Second, the organizational determinants 
describe the organizational requirements to enable the TSC mechanism. Third, the process determinants constitute the requirements regarding the process of the TSC mechanism and the process in which the TSC mechanism is embedded. Fourth, the relationship determinants are the requirements related to the relationship with the supply chain partners with which the TSC mechanism will be deployed. Fifth, the solution determinants describe the requirements for the TSC mechanism itself on an abstract level. In addition to the determinants in each group, the table provides a brief description of each determinant and mapping of the individual mechanisms. The number of cases in which each TSC determinant was found is shown in the corresponding cell.

Our analysis reveals that most TSC determinants are data determinants (ten of 29), followed by relationship determinants (six), solution determinants (five), and organizational and process determinants (both four). Also, the analysis suggests that five of the 29 TSC determinants (availability of data, relevant data, collaboration with partner, user acceptance, and userfriendliness) are relevant for all seven TSC mechanisms, and integration in process is relevant for all TSC mechanisms except mapping. In contrast, three TSC determinants (ease of data gathering, adequate relationship with partner, adaptability for data processing) are relevant only for a single TSC mechanism, and supportive actions for partner is relevant in only two cases.

As the case data reveals, not all TSC determinants are data determinants. Although each mechanism is enabled by data determinants, their dominance is not quite as high as the extant literature would suggest. Indeed, for the screening and assessing, mapping, and auditing mechanisms, only a few data determinants were found in our cases.

Insert Table 2 about here 


\section{DISCUSSION}

Our analysis reveals that all cases are united by their achievement to establish a fit between the IPN and IPC. To cope with uncertainty and satisfy the IPN, the focal companies in the cases tailored IPCs by the deployed TSC mechanisms. By contrasting the IPNs and TSC mechanisms, we identify 24 tailored solutions for the seven TSC mechanisms. In Cases 8, 15, 22, and 23, the IPN to increase the transparency of various performance dimensions of potential suppliers is matched with a comprehensive and rigorous screening and assessing mechanism that provides a comprehensive, multi-faceted, and multi-angle depiction of the suppliers. In all cases, a fit was achieved, which resulted in an enhanced level of transparency for the focal company. Hence, the cases suggest that establishing a fit between IPN and IPC is a requirement for enhancing TSC. However, this fit is not limited to the focal company; a fit between the IPN and IPC is also required for the corresponding supply chain partner. This is illustrated by the data determinants. For example, forecasting requires data accuracy and availability; as suppliers share data for a forecast with the focal company, they must build an adequate IPC to match the IPN to ensure accurate and available data. Our data confirm the general notion of IPT in the literature, which describes the fit as mandatory to achieve increased performance in general (e.g., Premkumar et al., 2005), however we emphasize the need to achieve this fit not only for the focal company but also for its relevant supply chain partners. Thereby, we underline the need of inter-organizational information processing and the fit, as we apply IPT to the inter-organizational level. Thereby, we simultaneously confirm and expand extant studies that draw on IPT on the intra-firm level, as our findings underline the general relationship between the fit and performance improvement at the intra-firm (confirmation) and the inter-organizational level (expansion). In line with Tushman and Nadler (1978) and Foerstl, Meinlschmidt, and Busse (2018), our interviewees confirm that a lower 
level of IPC leads to a reduced level of TSC and that a higher level of IPC would be economically inefficient, as enhancing TSC leads to costs. Based on this, we developed the first proposition:

Proposition 1: A fit between IPN and IPC is required to enhance TSC.

By looking more deeply at the unit of observation, we identified the determinants that are required to enable a specific TSC mechanism. Our analysis indicates homogeneity between the cases of each individual TSC mechanism, as evidenced by the low number of instances of case numbers in Table 2 (twelve cells, or $5.9 \%$ of the total of 203 cells). When comparing all cases across the TSC mechanisms, we find heterogeneity as well. Only five TSC determinants (availability of data, relevant data, collaboration with partner, user acceptance, and user-friendliness) are required for all TSC mechanisms, and only ten determinants (34\%) are associated with five or more TSC mechanisms. These results refine existing research on TSC in two ways. First, the case analysis emphasizes the importance of TSC determinants that go beyond the requirements of data (which we refer to as data determinants), in contrast to Williams et al. (2013), Srinivasan and Swink (2018), and Zhu et al. (2018), who limited their observations to data determinants. Our analysis suggests diversity among the required determinant groups, as each determinant group is associated with all TSC mechanisms. Second, the heterogeneity of the TSC mechanisms suggests that the TSC determinants are specific to the corresponding TSC mechanisms. In addition, the TSC determinants are not limited to the focal company; for example, relationship determinants must be attained by the relevant supply chain actors as well. This is evidenced by the fact that collaboration with supply chain partners is relevant to all TSC mechanisms. This finding led us to our second proposition: 
Proposition 2: Specific determinants have to be attained by the relevant supply chain actors to enable successful deployment of a TSC mechanism.

The case studies reveal that the TSC mechanisms, as IPCs, are built on IT, structures, and processes, as Bensaou and Venkatraman (1995) found for information processing in general. The data and solution determinants represent IT, the organizational determinants represent structures, and the process determinants represent the processes of each TSC mechanism. Furthermore, the relationship determinants of TSC mechanisms overlap with IT, structures, and processes in three ways. First, the supportive actions for partners determinant describes the requirement of supply chain actors to help others to enhance their IT capabilities. Second, the adequate relationship with the partner and common understanding determinants represent required inter-organizational structures. Third, the collaboration with partner and third parties and purposeful communication determinants represent the processes that are applied when deploying a TSC mechanism. Hence, TSC mechanisms are built on IT, structures, and processes at both the intra-firm and interorganizational levels. In order to attain variety in determinants and deploy a TSC mechanism, supply chain actors need to make investments, build up resources and skills for IT, and create structures and design processes at both the intra-firm and inter-organizational levels. In contrast to internal IT, structures, and processes, the inter-organizational level requires joint use of IOIS as a special form of IT; EDI, collaborative buyer-supplier meetings, and steering committees as interorganizational structures; and joint processes, such as collaborative training.

Our cases show that IT supports TSC mechanisms. Although the degree of support varies, all TSC mechanisms make use of IT and technology. Sensor technology, the IoT, and GPS technology are used for monitoring (Cases 3, 4, and 12) and to increase the availability, accuracy, accessibility, and timeliness of data (Cases 11, 18, and 20). Big data analytics and machine learning are applied 
to increase the accuracy, clarity, processability, and verifiability of data for forecasting (Cases 2, 7, 9, and 13), monitoring (Cases 5 and 12), and event watching (Cases 1, 19 and 21). EDI is used as an IOIS for data sharing along the supply chain, especially for forecasting (Cases 2, 7, 9, and 13), thereby enabling accessibility and availability of data as well as automated data processing and standardized data exchange. In addition to EDI, we studied a tracking and tracing solution in Case 14, which applied DLT as an IOIS to distribute information in a network and ensure the correctness and verifiability of data and adaptability of data processing. This was intended to ultimately achieve better traceability at the product level. Although the technology showed promise initially (Wang et al., 2019), DLT has only been applied in a single case. Thus, the benefits of this nascent technology for enhancing TSC still need to be demonstrated. Such IOISs are adopted and used at an inter-organizational level (e.g., Iacovou, Benbasat, \& Dexter, 1995). Our analysis confirms the supporting function of IT in enhancing TSC at the intra-firm level (Sanders \& Ganeshan, 2018; Srinivasan \& Swink, 2018; Zhu et al., 2018). However, we emphasize that supply chain partners require adequate IT as well. Based on this, we developed another proposition:

Proposition 3a: Attaining TSC determinants requires adequate intra-firm and inter-organizational IT from all relevant supply chain actors.

Structures at the intra-firm and inter-organizational level are also required to attain the determinants. At the intra-firm level, organizational structures establish clear responsibilities, interfunctional collaboration, and the availability of personal and trained users. For example, in Cases 6 and 10, the focal companies formalized preparation and training for an inter-functional auditing team. At the inter-organizational level, establishing exchange platforms, formalized meetings, and joint training improve relationships with the corresponding partners and targets to establish a common understanding between the involved supply chain partners. Cases 4,5 , and 17 showcase 
formalized meetings (mostly calls) between the buying firm and supplier to establish a common understanding of the key performance indicators for monitoring (Case 5) and the purpose and process of mapping (Cases 4 and 17). By identifying the relation between inter-organizational structures and TSC, we refine the findings of Daugherty et al. (2006), which prove the positive impact of structures in supply chains to enhance visibility. Hence, we developed the following proposition:

Proposition 3b: Attaining TSC determinants requires adequate intra-firm and inter-organizational structures from all relevant supply chain actors.

Furthermore, processes at the intra-firm and inter-organizational level are required to attain the determinants for specific TSC mechanisms. Process determinants at the intra-firm level are achieved by designing internal processes for TSC mechanisms and embedding the TSC mechanisms in well-established business processes. At the inter-organizational level, it is necessary to establish collaborative processes with the corresponding supply chain partners. In cases that involve event watching (Cases 1, 19, and 24), joint meetings and escalation procedures are implemented between the focal company and its suppliers as well as customers. With these findings, we expand the TSC literature, which to date has only examined the design of processes in relation to sustainable supply chains, in which traceability plays a key role (Foerstl et al., 2018). Thus, we developed an additional proposition:

Proposition 3c: Attaining TSC determinants requires adequate intra-firm and inter-organizational processes from all relevant supply chain actors.

Our case study of TSC elaborates on IPT in an inter-organizational context. From the perspective of the focal companies, which are led by uncertainties and resulting IPNs to deploy TSC 
mechanisms, this study determines the importance of intra-firm and inter-organizational information processing for enhancing TSC. Although suppliers (e.g., for forecasting in Cases 2, 7 , and 13) and buyers (e.g., for forecasting and event watching in Cases 1, 2, 7, 9, 13, and 19) benefit from enhanced TSC as well, the focal company is the main beneficiary. However, our data clearly indicate the importance of TSC determinants for the focal company and the corresponding supply chain partners to deploy a TSC mechanism, enable the fit, and thereby enhance TSC. Only by addressing these determinants at both the intra-firm and inter-organizational level can focal companies attain the determinants that lead to enhanced TSC. Thus, corresponding IT systems, structures, and processes must be established and used by the relevant supply chain partners as well. We expand on the extant IPT literature that focuses on the inter-organizational context of supply chains and develop a model of TSC, shown in Figure 1.

Insert Figure 1 about here

\section{CONCLUSION}

As the interest in TSC is increasing in both practice and academia, we conducted a multiple-case study to investigate how firms can enhance TSC, thereby addressing the research gap described by Swift et al. (2019). The explorative case study allowed us to place TSC in context, analyze the TSC mechanisms that are deployed to enhance TSC, and, ultimately, identify TSC determinants, including supportive IT, structures, and processes. We identified the importance of the fit between IPN and IPC. Moreover, we revealed the specific characteristics of TSC mechanisms by exploring the diversity of associated determinants. Along with this, we explored the different groups of determinants and the need to attain them through intra-firm and inter-organizational IT, structures, and processes. By drawing on IPT and synthesizing our findings, we built a model of TSC, which is shown in Figure 1. In this way, we contributed to both theory and practice. 


\section{Theoretical contribution}

Our theoretical contribution is threefold. First, we developed a model of TSC (Figure 1) that places the phenomenon in context, synthesizing and empirically expanding on existing TSC research (e.g., Barratt \& Oke, 2007; Williams et al., 2013) as well as helping to guide future research on this phenomenon. The developed model illustrates the five elements of TSC - motivations (uncertainties and IPN), antecedents (determinants and IT, structure and process requirements), TSC mechanisms (IPC), effects (TSC and targeted performance effect) and context - as well as their relationships. Thereby, the model provides a framework for future research on TSC, which might focus on individual elements of TSC or on individual TSC mechanisms. It is especially important to investigate individual mechanisms, as our study revealed heterogeneity between the seven TSC mechanisms.

Second, our study addresses the need for further clarification and operationalization of TSC (Wieland et al., 2016; Williams et al., 2013). We place TSC in context, providing a clearer picture of TSC and identifying the TSC determinants. As a result, we reveal how firms can enhance TSC. The determinants can be used to model TSC in future survey-based studies and can be applied as selection criteria in qualitative studies when researchers seek to study advanced levels of TSC. Moreover, future researchers can assess the benefit of a new technology at an early stage by analyzing its contributions to each determinant. The operationalization of the TSC mechanism allows them to base their argumentation on the revealed determinants.

Third, our study elaborates on IPT in the inter-organizational context of TSC using abductive reasoning, supplementing the studies of Williams et al. (2013), Srinivasan and Swink (2018), and Zhu et al. (2018). Our analysis suggests that intra-firm and inter-organizational alignment is important when focal companies seek to enhance TSC. While the literature on IPT mostly focuses 
on how organizations can be designed to establish a fit between IPN and IPC and thus improve performance in general (Galbraith, 1974; Tushman \& Nadler, 1978), our study contributes to the stream of inter-organizational research on IPT (i.e.,Bensaou \& Venkatraman, 1995; Premkumar et al., 2005). We go beyond extant literature and elaborate on the inter-organizational aspects of information processing that allow organizations to enhance TSC. Our study reveals that the motivation to enhance TSC and the target effects are mainly centered on the focal company, but in order to enhance TSC, the focal company greatly depends on the inter-organizational information processing of its supply chain partners. Hence, to enhance TSC, both the focal company and its supply chain partners must build intra-firm and inter-organizational IT, structures, and processes.

\section{Managerial contribution}

The managerial contribution of our study is also threefold. First, by placing TSC in context, we illustrate the existing relationships and dependencies between elements. Based on our model (Figure 1), supply chain managers can account for these relationships and dependencies during efforts to enhance TSC. Our study provides a clear picture of the causal relationships between the motivation to enhance TSC and antecedents and mechanisms.

Second, our study provides a clear list of required determinants to deploy specific TSC mechanisms to enhance TSC. Following our study, supply chain managers should analyze uncertainty and the resulting IPN to choose the appropriate TSC mechanism. Then, they should analyze the determinants and determine how they can build IT, structures, and processes to attain the relevant determinants for the chosen TSC mechanism. In addition, out study emphasis to collaborate with the relevant supply chain partners to foster the buildup of the requires IT, structures and processes early on. This will help supply chain managers enhance TSC and cope with perceived uncertainty. 
Furthermore, they can draw on the determinants and assess the attainment of IT, structures, and processes to identify reasons for low TSC after deploying a TSC mechanism.

Third, supply chain managers can use the identified determinants as a basis to assess the potential of novel technologies, such as DLT, for implementing a specific TSC mechanism and, ultimately, enhancing TSC. More specifically, managers can identify the technologies' contribution to attaining the required determinants for a TSC mechanism. For example, in the case of DLT, extant literature (Babich \& Hilary, 2019; Roeck, Sternberg, \& Hofmann, 2019; Schmidt \& Wagner, 2019; Wang et al., 2019) shows that DLT can contribute to the attainment of eight determinants: availability, accessibility, timeliness, processable, verifiable data, periodic update, automated data processing, and standardized data exchange. Seven of these are related to forecasting, and six are related to tracking and tracing. A brief initial assessment of DLT underlines the potential of the technology for both mechanisms. The list of determinants also allows managers to assess whether a technology is unsuitable or over-engineered for a specific TSC mechanism.

\section{REFERENCES}

Alvesson, M., \& Kärreman, D. (2007). Constructing mystery: Empirical matters in theory development. Academy of Management Review, 32(4), 1265-1281.

Aung, M. M., \& Chang, Y. S. (2014). Traceability in a food supply chain: Safety and quality perspectives. Food Control, 39, 172-184.

Babich, V., \& Hilary, G. (2019). Distributed ledgers and operations: What operations management researchers should know about blockchain technology. Manufacturing \& Service Operations Management. (in press).

Barratt, M., \& Oke, A. (2007). Antecedents of supply chain visibility in retail supply chains: A resource-based theory perspective. Journal of Operations Management, 25(6), 1217-1233.

Basole, R. C., \& Bellamy, M. A. (2014). Supply network structure, visibility, and risk diffusion: A computational approach. Decision Sciences, 45(4), 753-789.

Bensaou, M., \& Venkatraman, N. (1995). Configurations of interorganizational relationships: A comparison between U.S. and Japanese automakers. Management Science, 41(9), 1471-1492.

Bernstein, E. S. (2012). The transparency paradox: A role for privacy in organizational learning and operational control. Administrative Science Quarterly, 57(2), 181-216. 
Brandon-Jones, E., Squire, B., Autry, C. W., \& Petersen, K. J. (2014). A contingent resourcebased perspective of supply chain resilience and robustness. Journal of Supply Chain Management, 50(3), 55-73.

Brusset, X. (2016). Does supply chain visibility enhance agility? International Journal of Production Economics, 171, 46-59.

Caridi, M., Crippa, L., Perego, A., Sianesi, A., \& Tumino, A. (2010). Do virtuality and complexity affect supply chain visibility? International Journal of Production Economics, $127(2), 372-383$.

Carter, C. R., \& Easton, L. P. (2011). Sustainable supply chain management: Evolution and future directions. International Journal of Physical Distribution \& Logistics Management, $41(1), 46-62$.

Carter, C. R., \& Rogers, D. S. (2008). A framework of sustainable supply chain management: Moving toward new theory. International Journal of Physical Distribution \& Logistics Management, 38(5), 360-387.

Cegielski, C. G., Allison Jones-Farmer, L., wu, Y., \& Hazen, B. T. (2012). Adoption of cloud computing technologies in supply chains: An organizational information processing theory approach. The International Journal of Logistics Management, 23(2), 184-211.

Cheng, M. J., \& Simmons, J.E.L. (1994). Traceability in manufacturing systems. International Journal of Operations \& Production Management, 14(10), 4-16.

Costa, C., Antonucci, F., Pallottino, F., Aguzzi, J., Sarriá, D., \& Menesatti, P. (2013). A review on agri-food supply chain traceability by means of RFID technology. Food and Bioprocess Technology, 6(2), 353-366.

Cramer, J. M. (2008). Organising corporate social responsibility in international product chains. Journal of Cleaner Production, 16(3), 395-400.

Daugherty, P. J., Richey, R. G., Roath, A. S., Min, S., Chen, H., Arndt, A. D., \& Genchev, S. E. (2006). Is collaboration paying off for firms? Business Horizons, 49(1), 61-70.

Doorey, D. J. (2011). The transparent supply chain: From resistance to implementation at Nike and Levi-Strauss. Journal of Business Ethics, 103(4), 587-603.

Dubey, R., Gunasekaran, A., Childe, S. J., Papadopoulos, T., Luo, Z., \& Roubaud, D. (2017). Upstream supply chain visibility and complexity effect on focal company's sustainable performance: Indian manufacturers' perspective. Annals of Operations Research. Advance online publication.

Edmonson, A. C., \& McManus, S. E. (2007). Methodological fit in management field research. Academy of Management Review, 32(4), 1155-1179.

Egels-Zandén, N., Hulthén, K., \& Wulff, G. (2015). Trade-offs in supply chain transparency: The case of Nudie Jeans Co. Journal of Cleaner Production, 107(16), 95-104.

Eisenhardt, K. M. (1989). Building theories from case study research. Academy of Management Review, 14(4), 532-550.

Foerstl, K., Meinlschmidt, J., \& Busse, C. (2018). It's a match! Choosing information processing mechanisms to address sustainability-related uncertainty in sustainable supply management. Journal of Purchasing and Supply Management, 24(3), 204-217.

Galbraith, J. R. (1974). Organization design: An information processing view. Interfaces, 4(3), $28-36$. 
Gardner, J. T., \& Cooper, M. C. (2011). Strategic supply chain mapping approaches. Journal of Business Logistics, 24(2), 37-64.

Gerring, J. (2004). What is a case study and what is it good for? American Political Science Review, 98(02), 341-354.

Gioia, D. A., Corley, K. G., \& Hamilton, A. L. (2013). Seeking qualitative rigor in inductive research: Notes on the Gioia methodology. Organizational Research Methods, 16(1), 15-31.

Glaser, B. G. (1992). Basics of grounded theory analysis.: Sociology Press.

Glaser, B. G., \& Strauss, A. L. (1967). The Discovery of Grounded Theory: Strategies for Qualitative Research. New York: Aldine.

Gold, S., Seuring, S., \& Beske, P. (2010). Sustainable supply chain management and interorganizational resources: A literature review. Corporate Social Responsibility and Environmental Management, 17(4), 230-245.

Granados, N. F., Kauffman, R. J., \& King, B. (2008). How has electronic travel distribution been transformed? A test of the theory of newly vulnerable markets. Journal of Management Information Systems, 25(2), 73-96.

Gross, A. (2019). Tech paves way for transparency in supply chains: Consumers and investors demand to know the provenance of purchases and investments. Retrieved from Financial Times website: https://www.ft.com/content/033b9f2e-dfb5-11e9-b8e0-026e07cbe5b4

Gunasekaran, A., Subramanian, N., \& Rahman, S. (2015). Supply chain resilience: Role of complexities and strategies. International Journal of Production Research, 53(22), 68096819 .

Hofmann, E., Sternberg, H., Chen, H., Pflaum, A., \& Prockl, G. (2019). Supply chain management and Industry 4.0: Conducting research in the digital age. International Journal of Physical Distribution \& Logistics Management, 49(10), 945-955.

Holweg, M., Disney, S., Holmström, J., \& Småros, J. (2005). Supply chain collaboration: Making sense fo the strategy continuum. European Management Journal, 23(2), 170-181.

Iacovou, C. L., Benbasat, I., \& Dexter, A. S. (1995). Electronic data interchange and small organizations: Adoption and impact of technology. MIS Quarterly, 19(4), 465-485.

Ivanov, D., \& Dolgui, A. (2018). Low-Certainty-Need (LCN) supply chains: A new perspective in managing disruption risks and resilience. International Journal of Production Research, 118.

Jick, T. D. (1979). Mixing qualitative and quantitative methods: Triangulation in action. Administrative Science Quarterly, 24(4), 602-611.

Jin, Y. "H.”, Williams, B. D., Tokar, T., \& Waller, M. A. (2015). Forecasting with temporally aggregated demand signals in a retail supply chain. Journal of Business Logistics, 36(2), 199211.

Kärkkäinen, M., Ala-Risku, T., \& Främling, K. (2004). Efficient tracking for short-term multicompany networks. International Journal of Physical Distribution \& Logistics Management, 34(7), 545-564.

Kent, J. L., \& Mentzer, J. T. (2003). The effect of investment in interorganizational information technology in a retail supply chain. Journal of Business Logistics, 24(2), 155-175.

Ketokivi, M., \& Choi, T. (2014). Renaissance of case research as a scientific method. Journal of Operations Management, 32(5), 232-240. 
Kim, Y. H., \& Davis, G. F. (2016). Challenges for global supply chain sustainability: Evidence from conflict minerals reports. Journal of Business Logistics, 59(6), 1896-1916.

Kovács, G. (2008). Corporate environmental responsibility in the supply chain. Journal of Cleaner Production, 16(15), 1571-1578.

Liu, H., Ke, W., Wei, K. K., \& Hua, Z. (2013). The impact of IT capabilities on firm performance: The mediating roles of absorptive capacity and supply chain agility. Decision Support Systems, 54(3), 1452-1462.

McFarlane, D., \& Sheffi, Y. (2003). The impact of automatic identification on supply chain operations. International Journal of Logistics Management, 14(1), 1-17.

Meredith, J. (1998). Building operations management theory through case and field research. Journal of Operations Management, 16(4), 441-454.

Mighty Earth (2019). Cargill: The worst company in the world. Retrieved from https://stories.mightyearth.org/cargill-worst-company-in-the-world/index.html

Miller, J. W., Fugate, B. S., \& Golicic, S. L. (2017). How organizations respond to information disclosure: Testing alternative longitudinal performance trajectories. Academy of Management Journal, 60(3), 1016-1042.

Min, S., Zacharia, Z. G., \& Smith, C. D. (2019). Defining supply chain management: In the past, present, and future. Journal of Business Logistics, 40(1), 44-55.

Morgan, T. R., Richey, R. J. G., \& Ellinger, A. E. (2018). Supplier transparency: Scale development and validation. International Journal of Logistics Management, 4(1), 959-984.

Oliva, R., \& Watson, N. (2009). Managing functional biases in organizational forecasts: A case study of consensus forecasting in supply chain planning. Production and Operations Management, 18(2), 138-151.

Oliveira, R. R., Cardoso, I. M.G., Barbosa, J. L.V., da Costa, C. A., \& Prado, M. P. (2015). An intelligent model for logistics management based on geofencing algorithms and RFID technology. Expert Systems with Applications, 42(15), 6082-6097.

Premkumar, G. P., Ramamurthy, K., \& Saunders, C. S. (2005). Information processing view of organizations: An exploratory examination of fit in the context of interorganizational relationships. Journal of Management Information Systems, 22(1), 257-294.

Rauer, J., \& Kaufmann, L. (2015). Mitigating external barriers to implementing green supply chain management: A grounded theory investigation of green-tech companies' rare earth metals supply chains. Journal of Supply Chain Management, 51(2), 65-88.

Roeck, D. (2020). The foundation of distributed ledger technology for supply chain management. In Hawaii International Conference on System Science.

Roeck, D., Sternberg, H., \& Hofmann, E. (2019). Distributed ledger technology in supply chains: A transaction cost perspective. International Journal of Production Research, 1-18.

Saberi, S., Kouhizadeh, M., Sarkis, J., \& Shen, L. (2018). Blockchain technology and its relationships to sustainable supply chain management. International Journal of Production Research, 57(7), 2117-2135.

Sanders, N. R., \& Ganeshan, R. (2018). Big data in supply chain management. Production and Operations Management, 27(10), 1745-1748.

Schmidt, C. G., \& Wagner, S. M. (2019). Blockchain and supply chain relations: A transaction cost theory perspective. Journal of Purchasing and Supply Management, 25(4), 100552. 
Schnackenberg, A. K., \& Tomlinson, E. C. (2014). Organizational transparency: A new perspective on managing trust in organization-stakeholder relationships. Journal of Management, 42(7), 1784-1810.

Srinivasan, R., \& Swink, M. (2018). An investigation of visibility and flexibility as complements to supply chain analytics: An organizational information processing theory perspective. Production and Operations Management, 27(10), 1849-1867.

Steinfield, C., Markus, M. L., \& Wigand, R. T. (2011). Through a glass clearly: Standards, architecture, and process transparency in global supply chains. Journal of Management Information Systems, 28(2), 75-108.

Sternberg, H., Hofmann, E., \& Roeck, D. (2020). The struggle is real: Adoption insights from a supply chain blockchain case. Journal of Business Logistics, Forthcoming.

Swift, C., Guide Jr., V. D. R., \& Muthulingam, S. (2019). Does supply chain visibility affect operating performance? Evidence from conflict minerals disclosures. Journal of Operations Management, 65(5), 406-429.

Tomlin, B. (2006). On the value of mitigation and contingency strategies for managing supply chain disruption risks. Management Science, 52(5), 639-657.

Tushman, M. L., \& Nadler, D. A. (1978). Information processing as an integrating concept in organizational design. Academy of Management Review, 3(3), 613-624.

Urquhart, C. (2013). Grounded theory for qualitative research. a practical guide. Cathy Urquhart: SAGE.

Visich, J. K., Li, S., Khumawala, B. M., \& Reyes, P. M. (2009). Empirical evidence of RFID impacts on supply chain performance. International Journal of Operations \& Production Management, 29(12), 1290-1315.

Wadhwa, S., Mishra, M., Chan, F. T.S., \& Ducq, Y. (2010). Effects of information transparency and cooperation on supply chain performance: A simulation study. International Journal of Production Research, 48(1), 145-166.

Wamba, S. F., \& Chatfield, A. T. (2009). A contingency model for creating value from RFID supply chain network projects in logistics and manufacturing environments. European Journal of Information Systems, 18(6), 615-636.

Wan, Z., \& Beil, D. R. (2009). RFQ auctions with supplier qualification screening. Operations Research, 57(4), 934-949.

Wang, E. T. G., \& Wei, H.-L. (2007). Interorganizational governance value creation: Coordinating for information visibility and flexibility in supply chains. Decision Sciences, $38(4), 647-674$.

Wang, G., Gunasekaran, A., Ngai, E. W.T., \& Papadopoulos, T. (2016). Big data analytics in logistics and supply chain management: Certain investigations for research and applications. International Journal of Production Economics, 176, 98-110.

Wang, Y., Han, J. H., \& Beynon-Davies, P. (2018). Understanding blockchain technology for future supply chains: A systematic literature review and research agenda. Supply Chain Management: An International Journal. Advance online publication.

Wang, Y., Singgih, M., Wang, J., \& Rit, M. (2019). Making sense of blockchain technology: How will it transform supply chains? International Journal of Production Economics, 211, 221-236. 
Wieland, A., Handfield, R. B., \& Durach, C. F. (2016). Mapping the landscape of future research themes in supply chain management. Journal of Business Logistics, 37(3), 205-212.

Williams, B. D., Roh, J., Tokar, T., \& Swink, M. (2013). Leveraging supply chain visibility for responsiveness: The moderating role of internal integration. Journal of Operations Management, 31(7-8), 543-554.

Yaffe-Bellany, D. (2019). From environmental leader to 'worst company in the world'. Retrieved from https://www.nytimes.com/2019/07/29/business/brazil-deforestation-cargill.html

Yan, T., Choi, T. Y., Kim, Y., \& Yang, Y. (2015). A theory of the nexus supplier: A critical supplier from a network perspective. Journal of Supply Chain Management, 51(1), 52-66.

Yin, R. K. (2017). Case study research and applications: Design and methods (6. edition). Los Angeles, London, New Delhi, Singapore, Washington, DC: SAGE.

Zhu, S., Song, J., Hazen, B. T., Lee, K., \& Cegielski, C. (2018). How supply chain analytics enables operational supply chain transparency. International Journal of Physical Distribution \& Logistics Management, 48(1), 47-68.

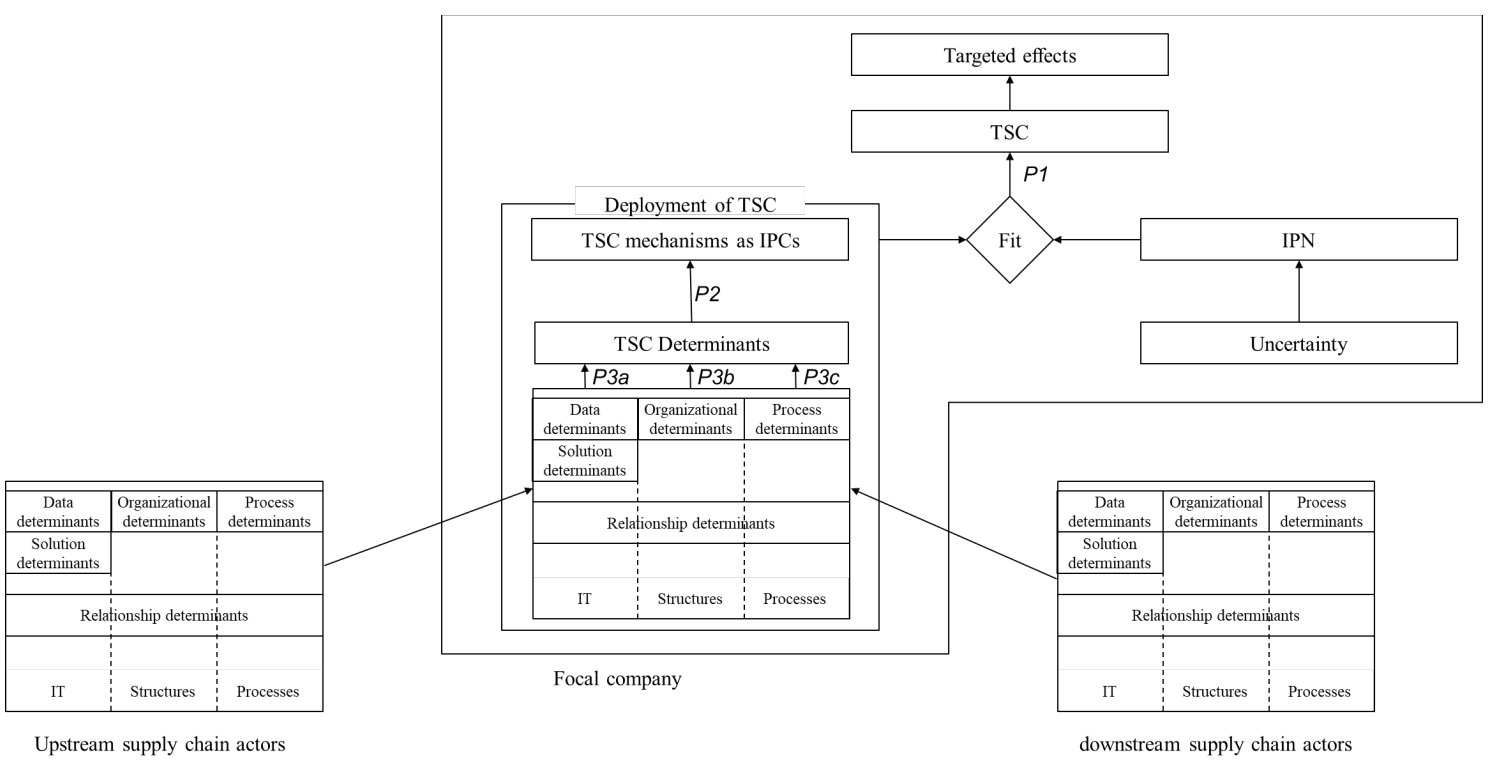

Figure 1: The model of enhanced TSC 
Table 1: Overview of cases

\begin{tabular}{|c|c|c|c|c|c|}
\hline $\begin{array}{l}\text { Case } \\
\text { ID }\end{array}$ & Industry & \begin{tabular}{|l|} 
Studied \\
mechanism
\end{tabular} & $\begin{array}{l}\text { Selection } \\
\text { criteria }\end{array}$ & Position of interviewees & $\begin{array}{l}\text { Total duration } \\
\text { in minutes }\end{array}$ \\
\hline 1 & Automotive & Ew & Award winner & $\begin{array}{l}\text { Head of Automotive Supply Chain Management, FC } \\
\text { Vice President Supply Chain Management, FC } \\
\text { Global Risk Manager, FC }\end{array}$ & 124 \\
\hline 2 & Semiconductor & Fo & Award winner & Principal Supply Chain Management. FC & 75 \\
\hline 3 & Pharmaceutical & Mo & Self-assessment & $\begin{array}{l}\text { Head Global Supply Chain, FC } \\
\text { Export Coordinator, FC } \\
\text { Logistics Coordinator, FC } \\
\text { Supply \& Demand Specialist, FC } \\
\text { Quality Control, FC } \\
\text { Product Owner, SP } \\
\text { Board Member, LSP }\end{array}$ & 429 \\
\hline 4 & Food & $\mathrm{Ma}$ & Self-assessment & $\begin{array}{l}\text { Head of Quality Management, FC } \\
\text { Supply Chain Management Specialist, FC } \\
\text { Head of Quality Management, S } \\
\text { Business Architect, SP }\end{array}$ & 267 \\
\hline 5 & Food & Mo & Self-assessment & $\begin{array}{l}\text { Head of Strategic Procurement Service/SCM, FC } \\
\text { Head of SCM Projects, FC }\end{array}$ & 100 \\
\hline 6 & Machinery & $\mathrm{Au}$ & Self-assessment & Head of Supply Chain Management, FC & 70 \\
\hline 7 & Machinery & Fo & Self-assessment & Head of Sales, FC & 74 \\
\hline 8 & Machinery & S\&A & Self-assessment & Supply Chain Management Specialist, FC & 88 \\
\hline 9 & Machinery & Fo & Self-assessment & $\begin{array}{l}\text { Value Chain Planning Manager, FC } \\
\text { Supply Chain Management Specialist, FC }\end{array}$ & 84 \\
\hline 10 & Machinery & $\mathrm{Au}$ & Self-assessment & $\begin{array}{l}\text { Lead Supplier Auditor, FC } \\
\text { Supply Chain Management Specialist, FC }\end{array}$ & 71 \\
\hline 11 & Automotive & $\mathrm{T} \& \mathrm{~T}$ & Award winner & Director Logistics Services, FC & 79 \\
\hline 12 & Pharmaceutical & Mo & Self-assessment & Global Head Environmental Supply Chain, FC & 84 \\
\hline 13 & Sanitation & Fo & Self-assessment & $\begin{array}{l}\text { Head of Global Supply Chain Management, FC } \\
\text { Head of Supply Management, FC }\end{array}$ & 131 \\
\hline 14 & Food & $\mathrm{T} \& \mathrm{~T}$ & Self-assessment & Head of Supply Chain Information Solutions, FC & 136 \\
\hline 15 & Transportation & S\&A & Self-assessment & $\begin{array}{l}\text { Strategic Purchasing Manager, FC } \\
\text { Category Manager IT, FC }\end{array}$ & 81 \\
\hline 16 & Transportation & $\mathrm{Au}$ & Self-assessment & $\begin{array}{l}\text { Strategic Purchasing Manager, FC } \\
\text { Category Manager IT, FC }\end{array}$ & 75 \\
\hline 17 & Machinery & $\mathrm{Ma}$ & Self-assessment & Head of Supply Chain Management, FC & 140 \\
\hline 18 & Automotive & $\mathrm{T} \& \mathrm{~T}$ & Award winner & $\begin{array}{l}\text { Product Supply Chain Solutions, FC } \\
\text { Senior Manager Material Control, FC }\end{array}$ & 105 \\
\hline 19 & Automotive & Ew & Self-assessment & $\begin{array}{l}\text { Corporate Supply Chain Manager, FC } \\
\text { Business Developer, SP }\end{array}$ & 116 \\
\hline 20 & Automotive & $\mathrm{T} \& \mathrm{~T}$ & Award winner & Project Manager, FC & 79 \\
\hline 21 & Machinery & $\mathrm{Ma}$ & Self-assessment & $\begin{array}{l}\text { Head of Sourcing Excellence, FC } \\
\text { Head of Corporate Risk, FC } \\
\text { Project Manager Sourcing Excellence, FC }\end{array}$ & 146 \\
\hline 22 & Pharmaceutical & S\&A & Self-assessment & $\begin{array}{l}\text { Head of Global Supply Chain, FC } \\
\text { Purchasing Manager, FC }\end{array}$ & 96 \\
\hline 23 & Cosmetics & S\&A & Self-assessment & $\begin{array}{l}\text { Head of Raw Material Sourcing, FC } \\
\text { Vice President Supply Chain Management, FC }\end{array}$ & 89 \\
\hline 24 & Aerospace & Ew & Self-assessment & $\begin{array}{l}\text { Vice President Supply Chain Management, FC } \\
\text { Managing Director, SP }\end{array}$ & 214 \\
\hline
\end{tabular}

\section{FC Focal company}

S Supplier company
SP Service provider

LSP Logistics service provider 
Table 2: TSC determinants

\begin{tabular}{|c|c|c|c|c|c|c|c|c|c|c|c|}
\hline & Determinant & Description & $\begin{array}{l}\text { S\&A } \\
(8,15 \\
22,23)\end{array}$ & $\begin{array}{l}\text { Fo } \\
(2,7 \\
9,13)\end{array}$ & $\begin{array}{l}\text { Mo } \\
(3,5 \\
12)\end{array}$ & $\begin{array}{l}\text { T\&T } \\
(11,14 \\
18,20)\end{array}$ & $\begin{array}{l}\text { Ma } \\
(4,17, \\
21)\end{array}$ & $\begin{array}{l}\mathbf{E W} \\
(1,19 \\
24)\end{array}$ & $\begin{array}{l}\text { Au } \\
(6,10 \\
16)\end{array}$ & $\begin{array}{l}\text { In number } \\
\text { of TSC } \\
\text { mechanisms }\end{array}$ & $\begin{array}{l}\text { Count in } \\
\text { all cases }\end{array}$ \\
\hline \multirow{10}{*}{ 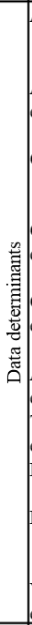 } & Accuracy of data & $\begin{array}{l}\text { TSC mechanism depends on } \\
\text { accurate input data and has to } \\
\text { provide accurate output data }\end{array}$ & $\mathrm{N}$ & $\bar{A}$ & A & $\mathrm{N}$ & $\mathrm{N}$ & A & $\mathrm{N}$ & 3 & 10 \\
\hline & $\begin{array}{l}\text { Availability of } \\
\text { data }\end{array}$ & $\begin{array}{l}\text { TSC mechanism depends on data } \\
\text { availability and has to make } \\
\text { output data available }\end{array}$ & A & A & A & A & A & A & A & 7 & 24 \\
\hline & Clarity of data & $\begin{array}{l}\text { TSC mechanism depends on } \\
\text { clarity of data and has to provide } \\
\text { clear output data }\end{array}$ & $\mathrm{N}$ & A & A & $\mathrm{N}$ & A & A & $\mathrm{N}$ & 4 & 13 \\
\hline & $\begin{array}{l}\text { Completeness of } \\
\text { data }\end{array}$ & $\begin{array}{l}\text { f TSC mechanism depends on } \\
\text { complete input data and has to } \\
\text { provide complete output data }\end{array}$ & $\mathrm{N}$ & $\mathrm{N}$ & A & A & $\mathrm{N}$ & A & A & 4 & 13 \\
\hline & $\begin{array}{l}\text { Correctness of } \\
\text { data }\end{array}$ & $\begin{array}{l}\text { TSC mechanism depends on } \\
\text { correct input data and has to } \\
\text { provide correct output data }\end{array}$ & A & A & A & $\mathrm{N}$ & 4 & A & A & 5 & 18 \\
\hline & $\begin{array}{l}\text { Accessibility of } \\
\text { data }\end{array}$ & $\begin{array}{l}\text { TSC mechanism depends on } \\
\text { accessible input data }\end{array}$ & $\mathrm{N}$ & A & A & A & $\mathrm{N}$ & $\mathrm{N}$ & $\mathrm{N}$ & 3 & 11 \\
\hline & $\begin{array}{l}\text { Timeliness of } \\
\text { data }\end{array}$ & $\begin{array}{l}\text { TSC mechanism depends on } \\
\text { accessible input data }\end{array}$ & $\mathrm{N}$ & A & A & A & $\mathrm{N}$ & A & $\mathrm{N}$ & 4 & 14 \\
\hline & Processable data & $\begin{array}{l}\text { TSC mechanism depends on } \\
\text { processable input data }\end{array}$ & A & A & A & A & $\mathrm{N}$ & $\mathrm{N}$ & $\mathrm{N}$ & 4 & 15 \\
\hline & Relevant data & $\begin{array}{l}\text { TSC mechanism depends on } \\
\text { relevant input data and has to } \\
\text { provide relevant output data }\end{array}$ & A & A & A & A & $\mathrm{A}$ & A & A & 7 & 24 \\
\hline & $\begin{array}{l}\text { Verifiability of } \\
\text { data }\end{array}$ & $\begin{array}{l}\text { TSC mechanism depends on } \\
\text { verifiable input data }\end{array}$ & A & $\mathrm{N}$ & $\mathrm{N}$ & $\mathrm{N}$ & A & 1,19 & A & 3 & 12 \\
\hline \multirow{4}{*}{ 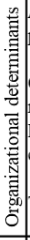 } & $\begin{array}{l}\text { Availability of } \\
\text { personal }\end{array}$ & $\begin{array}{l}\text { TSC mechanism requires } \\
\text { involvement of specific personal } \\
\text { with their expertise }\end{array}$ & $\mathrm{N}$ & $\mathrm{N}$ & $\mathrm{N}$ & $\mathrm{N}$ & A & $\mathrm{N}$ & A & 2 & 6 \\
\hline & $\begin{array}{l}\text { Clear } \\
\text { responsibility }\end{array}$ & $\begin{array}{l}\text { TSC mechanism requires clear } \\
\text { role and task understanding }\end{array}$ & $\mathrm{N}$ & $\mathrm{N}$ & $\mathrm{N}$ & A & A & $\mathrm{N}$ & A & 3 & 10 \\
\hline & $\begin{array}{l}\text { Interfunctional } \\
\text { collaboration }\end{array}$ & $\begin{array}{l}\text { TSC mechanism builds on } \\
\text { interfunctional collaboration with } \\
\text { the FC }\end{array}$ & A & A & A & $\mathrm{N}$ & A & A & A & 6 & 20 \\
\hline & Trained users & $\begin{array}{l}\text { TSC mechanism requires adequate } \\
\text { training of users in beforehand }\end{array}$ & $\mathrm{N}$ & $\mathrm{N}$ & $\mathrm{N}$ & $\mathrm{N}$ & $\mathrm{N}$ & A & A & 2 & 6 \\
\hline \multirow{4}{*}{ 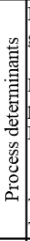 } & $\begin{array}{l}\text { Ease of data } \\
\text { gathering }\end{array}$ & $\begin{array}{l}\text { Data gathering has to be } \\
\text { performed with little effort and at } \\
\text { best automatically }\end{array}$ & $\mathrm{N}$ & 7 & 3 & A & $\mathrm{N}$ & $\mathrm{N}$ & $\mathrm{N}$ & 1 & 6 \\
\hline & $\begin{array}{l}\text { Integration in } \\
\text { processes }\end{array}$ & $\begin{array}{l}\text { TSC mechanism has to be } \\
\text { embedded in business processes }\end{array}$ & A & A & A & A & $\mathrm{N}$ & A & A & 6 & 21 \\
\hline & Periodic update & $\begin{array}{l}\text { TSC mechanism requires an } \\
\text { update within a pre-defined } \\
\text { timespan }\end{array}$ & A & A & $\mathrm{N}$ & $\mathrm{N}$ & A & A & A & 5 & 17 \\
\hline & $\begin{array}{l}\text { Timely use of } \\
\text { TSC mechanism }\end{array}$ & $\begin{array}{l}\text { TSC mechanism has to be applied } \\
\text { at the right time }\end{array}$ & A & $\mathrm{N}$ & $\mathrm{N}$ & A & $\mathrm{N}$ & A & 16 & 3 & 12 \\
\hline \multirow{6}{*}{ 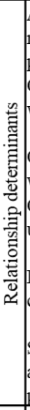 } & $\begin{array}{l}\text { Adequate } \\
\text { relationship with } \\
\text { partner }\end{array}$ & $\begin{array}{l}\text { TSC mechanism requires an } \\
\text { adequate relationship with supply } \\
\text { chain partner or third party SP }\end{array}$ & $\mathrm{N}$ & $\mathrm{N}$ & $\mathrm{N}$ & 18 & $\mathrm{~A}$ & $\mathrm{~N}$ & $\mathrm{~N}$ & 1 & 4 \\
\hline & $\begin{array}{l}\text { Collaboration } \\
\text { with partner }\end{array}$ & $\begin{array}{l}\text { TSC mechanism requires close } \\
\text { collaboration with supply chain } \\
\text { partner }\end{array}$ & A & A & A & A & A & A & A & 7 & 24 \\
\hline & $\begin{array}{l}\text { Collaboration } \\
\text { with third party }\end{array}$ & $\begin{array}{l}\text { TSC mechanism requires close } \\
\text { collaboration with third party SP }\end{array}$ & 8 & $\mathrm{~N}$ & $\mathrm{~N}$ & A & A & A & $\mathrm{N}$ & 3 & 11 \\
\hline & $\begin{array}{l}\text { Common } \\
\text { understanding }\end{array}$ & $\begin{array}{l}\text { TSC mechanism builds on } \\
\text { common understanding of all } \\
\text { involved parties }\end{array}$ & $\mathrm{N}$ & $\mathrm{N}$ & A & A & A & A & $\mathrm{N}$ & 4 & 13 \\
\hline & $\begin{array}{l}\text { Purposeful } \\
\text { communication }\end{array}$ & $\begin{array}{l}\text { TSC mechanism requires effective } \\
\text { and efficient communication } \\
\text { between all involved parties }\end{array}$ & 8 & $\mathrm{~N}$ & $\mathrm{~N}$ & $\mathrm{~N}$ & A & 24 & A & 2 & 8 \\
\hline & $\begin{array}{l}\text { Supportive } \\
\text { actions for } \\
\text { partner }\end{array}$ & $\begin{array}{l}\text { TSC mechanism requires supply } \\
\text { chain actors to help each other } \\
\text { establishing the mechanism }\end{array}$ & $\mathrm{N}$ & 13 & $\mathrm{~N}$ & 18 & $\mathrm{~N}$ & $\mathrm{~N}$ & $\mathrm{~N}$ & 0 & 2 \\
\hline \multirow{5}{*}{ 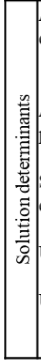 } & $\begin{array}{l}\text { Adaptability for } \\
\text { data processing }\end{array}$ & $\begin{array}{l}\text { TSC mechanism builds on } \\
\text { adaptable IT infrastructure that } \\
\text { accounts for heterogeneity and } \\
\text { multiple interfaces }\end{array}$ & $\mathrm{N}$ & A & $\mathrm{N}$ & 14 & $\mathrm{~N}$ & $\mathrm{~N}$ & $\mathrm{~N}$ & 1 & 5 \\
\hline & $\begin{array}{l}\text { Automated data } \\
\text { processing }\end{array}$ & $\begin{array}{l}\text { TSC mechanism requires } \\
\text { automated processing of input } \\
\text { data }\end{array}$ & $\mathrm{N}$ & A & $\mathrm{N}$ & A & $\mathrm{N}$ & A & $\mathrm{N}$ & 3 & 11 \\
\hline & $\begin{array}{l}\text { Standardized } \\
\text { data exchange }\end{array}$ & $\begin{array}{l}\text { TSC mechanism requires } \\
\text { standardized data (incl. master } \\
\text { data) and data exchange }\end{array}$ & $\mathrm{N}$ & A & A & A & A & A & $\mathrm{N}$ & 5 & 17 \\
\hline & User acceptance & $\begin{array}{l}\text { TSC mechanism requires the } \\
\text { acceptance of all involved users }\end{array}$ & A & A & A & A & A & A & A & 7 & 24 \\
\hline & User friendliness & $\begin{array}{l}\text { TSC mechanism builds on user } \\
\text { friendliness for ease of operational } \\
\text { use }\end{array}$ & A & A & A & A & A & A & A & 7 & 24 \\
\hline
\end{tabular}
A In all cases of this
$\mathrm{N}$ In none of the cases mechanism 